\title{
MICROSCOPY AND MICROANALYSIS 2002
}

\section{Letter from the Retiring Editor}

\author{
G. W. BAILEY \\ PROCEEDINGS EDITOR
}

\section{FAREWELL}

In 1966, John Watson asked Claude Arceneaux and me to develop and arrange a Proceedings Publication for the 1967 Meeting of the Electron Microscopy Society of America, to commemorate the 25th Annual Meeting of the Society. Thus, the Proceedings was born. We thought it would be a one year deal—now we are publishing our 2002 Proceedings. The EMSA/MSA Proceedings has become an internationally recognized publication of the Society and has been enhanced by the other participating Societies such as the Microbeam Analysis Society, the Microscopical Society of Canada, the Histochemical Society, and the International Metallographic Society. As participation has grown, the Proceedings has been able to adapt to the changes. I believe that we have a first class Proceedings that serves all participating Societies to the fullest! I am proud of what the Proceedings has done for MSA, for the science of microscopy, and for all of the participating Societies.

Beginning in 1967, I have been a volunteer worker. Although I have never received nor expected any monetary payment for being Proceedings Editor, I have received the most valued reward that could ever be expected: serving a great society, MSA, and experiencing the fellowship, friendship, and above all, the respect of my many friends in MSA and in the participating Societies. How could I be so fortunate? It has been wonderful and in my now Southern tradition, thanks to "you all".

The M\&M Proceedings will take on a new look for 2002. We will have a combination hard copy Proceedings for invited papers and a CD for all papers-invited papers and contributed papers. We are fortunate in having a new Proceedings Editor, Stuart McKernan, and a new Publisher, Cambridge University Press, represented by Ed Barnas. They will both do an excellent job.

At the risk of not acknowledging someone special, I want to say thanks to some people who have made my "career" as Proceedings Editor something special: Ron Anderson-we have worked together for 30 plus years; Charlie Lyman-I trained him as a Program Chair and now he is my Editor-in-Chief; Dale Johnson, Bob Fisher, and Barbara Reine who got me through the 1990 International Meeting; Charles Susskind, who was our San Francisco Press Publisher for many years; Herb Niemerow, our most recent Publisher's representative who gave us a great five years; to the Rebedeau Group: to the Bostrom organization; to Mort and Larry Maser; and to my wife, Pat, who did all of my typing, offered support, and helped me to always have the material to the publisher on schedule. Above all, I thank MSA for many great years and hope that MSA, the Proceedings, and the Baileys have many great years ahead. 